\title{
Novel donors of nitric oxide derived of S-nitrosocysteine possessing antioxidant activities
}

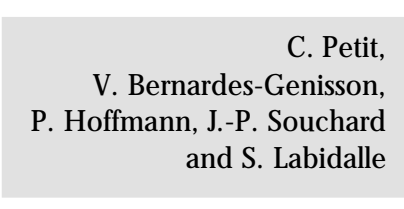

Correspondence
V. Bernardes-Genisson
Laboratoire de Synthèse,
Physico-Chimie et Radiobiologie
Faculté des Sciences Pharmaceutiques
35 chemin des M araîchers
31062 Toulouse Cedex 04
France
Fax: + 33-5-6226-2633
E-mail: genisson@ cict.fr
Presented at the M eeting
"NO Brazil, Basic and Clinical
Aspects of Nitric O xide",
Foz do Iguaçu, PR, Brazil,
March 10-13, 1999.

Received June 17, 1999 Accepted July 28, 1999

\section{Abstract}

Novel $S$-nitrosothiols possessing a phenolic function were investigated as nitric oxide (NO) donors. A study of NO release from these derivatives was carried out by electron spin resonance (ESR). All compounds gave rise to a characteristic three-line ESR signal in the presence of the complex [Fe(II)(MGD) $)_{2}$, revealing the formation of the complex $\left[\mathrm{Fe}(\mathrm{II})(\mathrm{MGD})_{2}(\mathrm{NO})\right]$. Furthermore, tests based on cytochrome $\mathrm{c}$ reduction were performed in order to study the ability of each phenolic disulfide, the final organic decomposition product of $S$ nitrosothiols, to trap superoxide radical anion $\left(\mathrm{O}_{2}^{-}\right)$. This study revealed a high reactivity of $1 \mathrm{~b}$ and $3 \mathrm{~b}$ towards $\mathrm{O}_{2}{ }^{-}$. For these two compounds, the respective inhibitory concentration (IC) 50 values were $92 \mu \mathrm{M}$ and $43 \mu \mathrm{M}$.

\section{Introduction}

The nitric oxide (NO) radical is an important and versatile mediator in biological systems (1). This molecule is known to play an important role in the regulation of a wide range of physiological processes. NO is biosynthesized from L-arginine by NO synthases (NOS) in a two-step oxidation process (2) and has an extremely short lifetime. In order to increase its stability to reach its biological targets, NO radical must be carried by chemical species. It has been suggested that NO radical is stabilized in vivo by reactions with molecules such as proteins containing nucleophilic residues or bioinorganic molecules $(3,4)$.

The physiological role of the NO radical involves cellular immunity (5), neurotransmission (6), inhibition of platelet aggregation (7), and particularly dilation of blood vessels (8). In the case of pathological states which are associated with a lack of NO (angina pectoris), this molecule can be administered by inhalation or by NO donor molecules. A great interest has thus arisen in NO donors such as sodium nitroprusside (9), Roussin's salts $(10,11)$, organic nitrates (12) and nitrites (13), furoxans (14,15), diazenium diolates $(16,17), \alpha-\beta$ ethylenic oximes (18), and $S$-nitrosothiols $(19,20)$ (also named thionitrites), due to their application in medicinal therapy and in pharmacology.

Among the most important natural carriers of nitric oxide are $S$-nitrosoalbumin, $S$ nitrosoglutathione and $S$-nitrosocysteine (21). Once thiols are converted to $S$-nitrosothiols, these molecules release NO by a homolytic break of the S-N bond. Sulfhydryl radicals then couple to give rise to symmetrical disulfide $(19,20)$. 
$2 \mathrm{RS}-\mathrm{NO} \rightarrow 2 \mathrm{NO}+\mathrm{RS}-\mathrm{SR}$ (Equation 1)

In contrast to the beneficial activities of $\mathrm{NO}$, abnormally high levels of this radical can be deleterious to the cell. This toxicity has been partially attributed to the formation of peroxynitrite anion $\left(\mathrm{ONOO}^{-}\right)$via reaction of the NO radical with superoxide radical anion $\left(\mathrm{O}_{2}^{-}\right)(22)$.

\section{$\mathrm{NO}+\mathrm{O}_{2}^{-} \rightarrow \mathrm{ONOO}^{-}$}

(Equation 2)

Peroxynitrous acid formed thereafter induces the oxidation of cell membranes as well as iron/sulfur centers $(23,24)$.

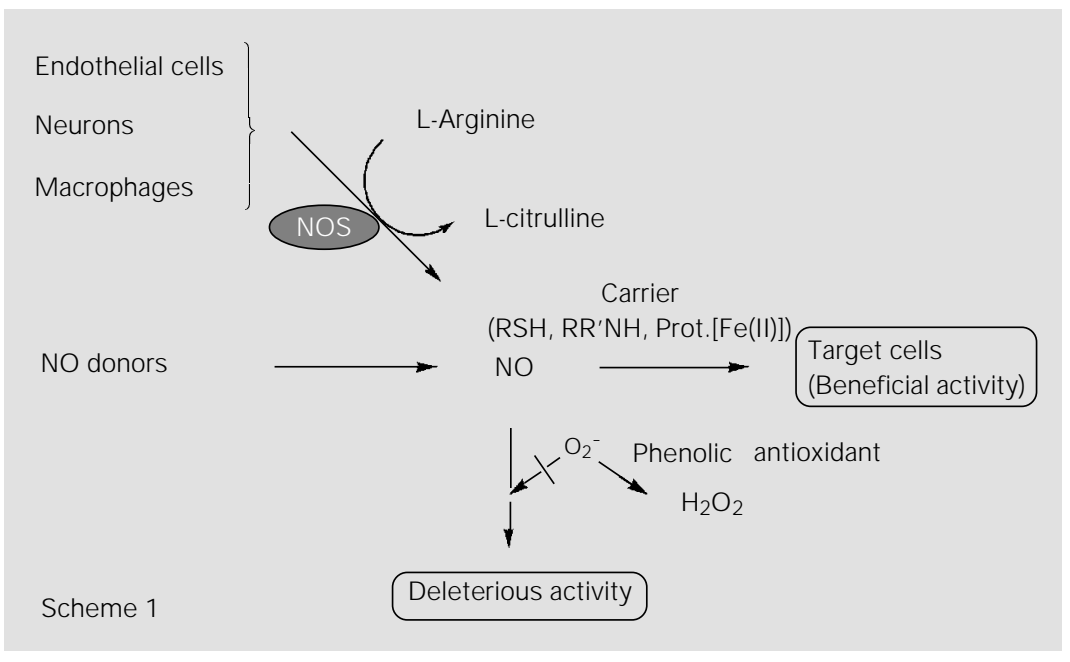

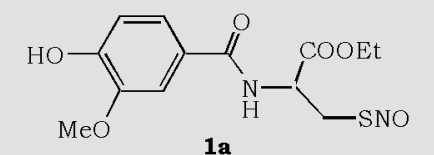

1a

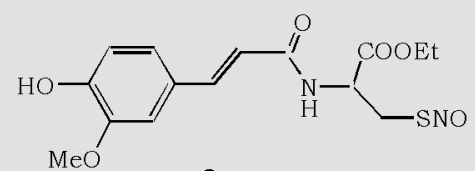

3a
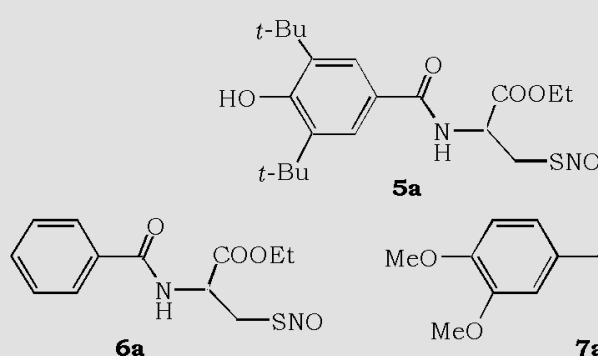

6a

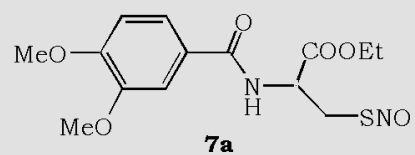

Scheme 2
Our group has recently developed the concept of an original NO carrier by which $S$-nitrosothiol is conjugated with an antioxidant molecule in order to couple two complementary activities: NO release and scavenging of the free superoxide radical present in the biological environment to inhibit the subsequent formation of peroxynitrite (Scheme 1).

We have synthesized novel $S$-nitrosocysteine derivatives denoted 1a-5a (depicted in Scheme 2) associated with various phenolic acids, some of which are known in the literature for their efficiency as scavengers of superoxide radical $(25,26)$.

In the present study we investigated whether the association of these two functions interferes with NO release and tested the reactivity of the antioxidant moiety towards the superoxide radical. As a control, the same study was carried out on $S$-nitrosothiols possessing no such phenolic moiety (molecules 6a and 7a depicted in Scheme 2) under identical conditions as for thionitrites $1 \mathrm{a}-5 \mathrm{a}$.

We present herein studies of the NO release from derivatives 1a-7a and of the ability of each disulfide ( $1 b-7 b)$, produced simultaneously to NO release, to trap the superoxide radical.

\section{Results and Discussion}

\section{Study of NO radical release}

The NO radical originating from the decomposition of $S$-nitrosothiols 1 a-7a was indirectly detected by electron spin resonance (ESR) spectroscopy via a reaction with the inorganic complex [Fe(II)(MGD) $)_{2}$, generated with Mohr's salt $\left[\mathrm{Fe}(\mathrm{II})\left(\mathrm{SO}_{4}\right)_{2}\left(\mathrm{NH}_{4}\right)_{2}\right]$ and with a large excess of $N$-methyl glycamyl dithiocarbamate (MGD) in water. Despite being paramagnetic, NO cannot be directly detected by ESR spectroscopy because of its very low stability in solution. It can, however, be detected when it is trapped by the 
ferrous complex at room temperature to yield a radical adduct (27).

$S$-nitrosothiols $1 \mathrm{a}-7 \mathrm{a}$ at $0.1 \mathrm{mM}$ in a mixture of $99 \%$ water and $1 \%$ DMF and in the presence of $2 \mathrm{mM}\left[\mathrm{Fe}(\mathrm{II})(\mathrm{MGD})_{2}\right]$ gave rise to a characteristic three-line ESR signal (with a hyperfine splitting constant $a_{\mathrm{N}}=12.85 \mathrm{G}$ ), depicted in Figure 1.

In aqueous medium, corresponding disulfides were obtained as the sole final organic decomposition products for each case, revealing that the presence of phenolic function for thionitrites 1a-5a did not obstruct a quantitative NO release from these compounds. The disulfides $1 \mathrm{~b}-5 \mathrm{~b}$ generated during NO release are expected to possess an antioxidant effect towards reactive oxygen species due to their phenolic moiety.

\section{Study of the ability of the disulfides to trap superoxide radical}

In order to check whether the novel compounds $1 b-5 b$ would retain their ability to trap superoxide radical, colorimetric tests with cytochrome c were carried out. As a control, these tests were also performed with disulfides possessing no phenolic group (6b and $7 b$ ). Superoxide radical is generated by the xanthine-xanthine oxidase system in the presence of cytochrome $\mathrm{c}$, itself reduced by this radical. Reduced cytochrome c absorbs at $550 \mathrm{~nm}$ (28). Inhibition of this reaction by various concentrations of the compounds studied was therefore monitored at this wavelength.

Our results describe various behaviors of each derivative at $100 \mu \mathrm{M}$ in $50 \mathrm{mM}$ phosphate buffer. None of the disulfides $5 \mathrm{~b}, 6 \mathrm{~b}$ or $7 \mathrm{~b}$ had any effect on the reduction of cytochrome c. Compounds $2 \mathrm{~b}$ and $4 \mathrm{~b}$ trapped superoxide radical by as much as 13 and $19 \%$, respectively. On the other hand, compounds $1 \mathrm{~b}$ and $3 \mathrm{~b}$ were capable of inhibiting the reduction of cytochrome $\mathrm{c}$ under identical conditions by as much as 55 and $100 \%$, respectively.
In order to investigate whether phenolic compounds $1 \mathrm{~b}-4 \mathrm{~b}$ could influence enzyme activity (i.e., xanthine oxidase), uric acid production was monitored by following its absorbance at $291 \mathrm{~nm}$ (28). These molecules did not decrease the rate of formation of uric acid, implying that compounds $1 \mathrm{~b}-4 \mathrm{~b}$ do not inhibit xanthine oxidase.

To establish a concentration corresponding to $50 \%$ of inhibition (IC 50) for com-

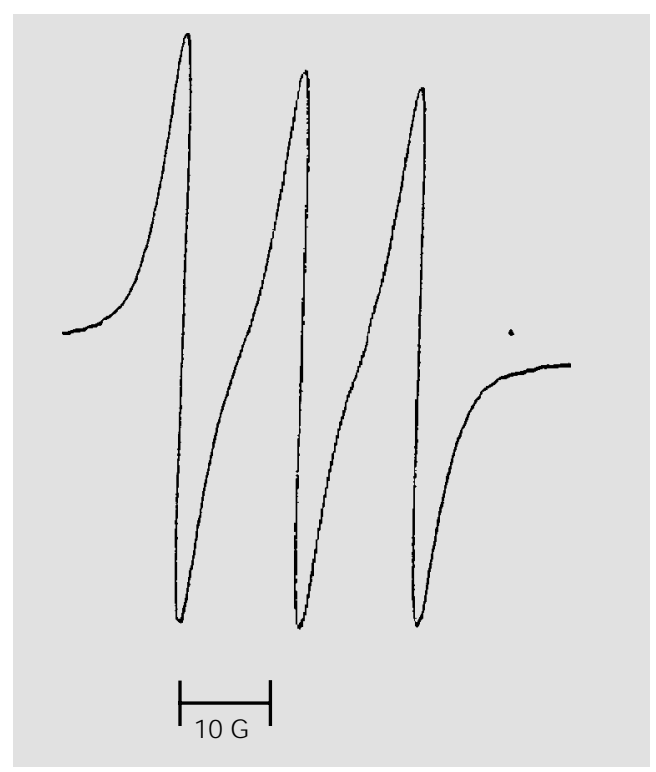

Figure 1 - ESR trapping of NO radical obtained from 1a-5a (0.1 $\mathrm{mM}$ ) in $\mathrm{DMF} / \mathrm{H}_{2} \mathrm{O}: 1 / 99$.

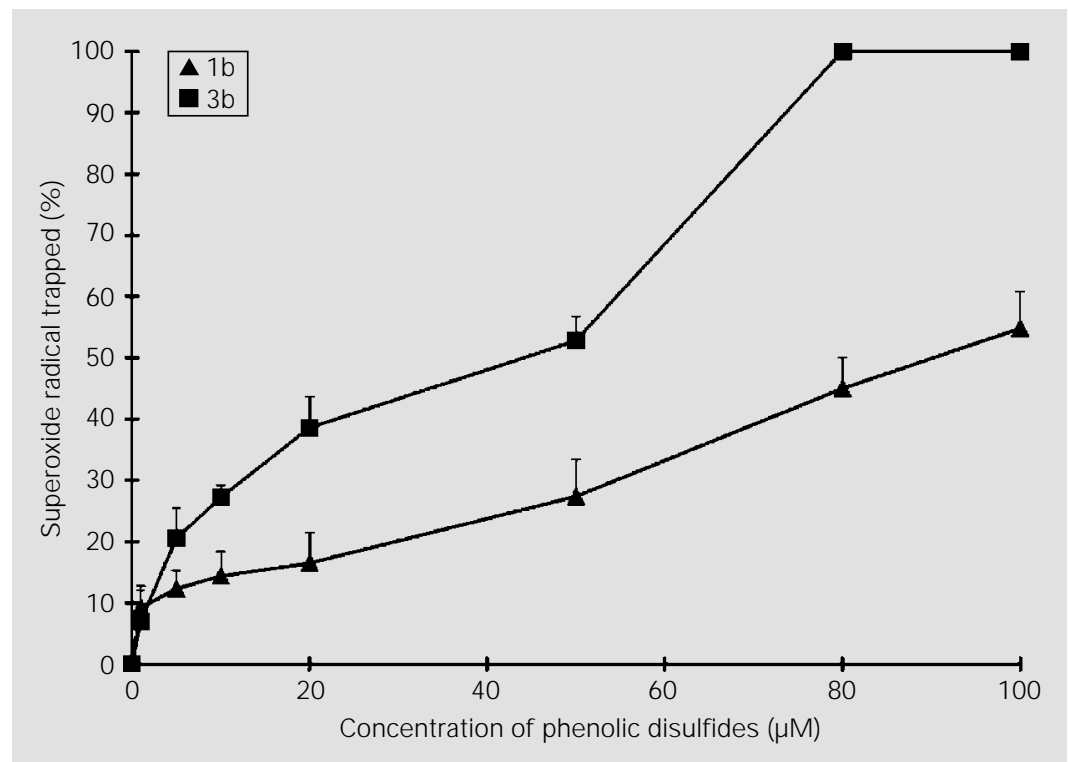

Figure 2 - Inhibition of cytochrome c reduction by disulfides $1 \mathrm{~b}$ and $3 \mathrm{~b}(1-100 \mu \mathrm{M})$ in $50 \mathrm{mM}$ phosphate buffer, $\mathrm{pH}=6.9$. 
Figure 3 - Concentration of disulfides $1 \mathrm{~b}$ and $3 \mathrm{~b}$ for $50 \%$ of cytochrome $\mathrm{c}$ reduction inhibition. pounds $1 \mathrm{~b}$ and $3 \mathrm{~b}$, i.e., those giving the most interesting results, new tests were carried out at concentrations between $1 \mu \mathrm{M}$ and 100 $\mu \mathrm{M}$ (Figure 2).

The IC 50 values for both disulfides were

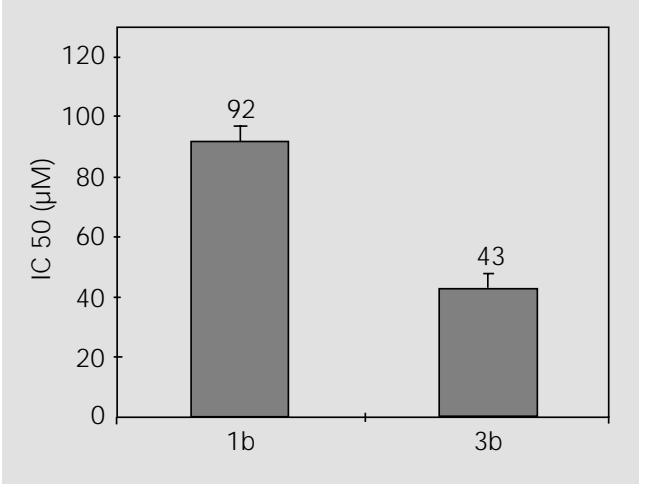

determined from this graph and are depicted in Figure 3.

A possible structure-activity relationship can be deduced from this experiment: disulfides possessing a para phenolic hydroxyl (in relation to amides or vinyl-amides (1b and $3 \mathrm{~b}$ )) are more reactive towards $\mathrm{O}_{2}^{-}$than those possessing a meta phenolic hydroxyl ( $2 b$ and $4 b$ ).

Moreover, compound $3 \mathrm{~b}$, possessing an $\alpha-\beta$ ethylenic amide group rather than only a para amide funtionality, is more active than compound $1 \mathrm{~b}$.

These results are in agreement with the fact that these phenolic compounds react with $\mathrm{O}_{2}^{-}$radical by a radical mechanism to give quinone-like compounds: phenoxy radi-

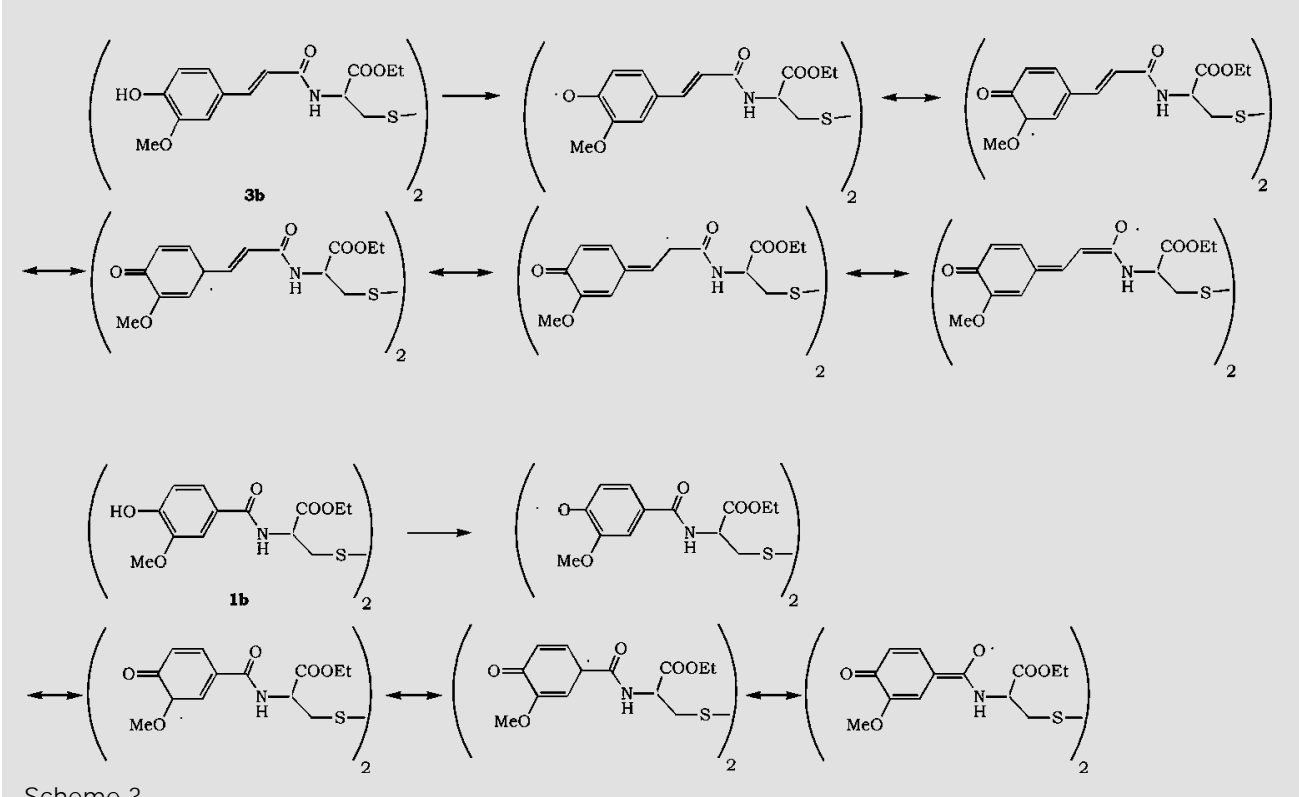

Scheme 3

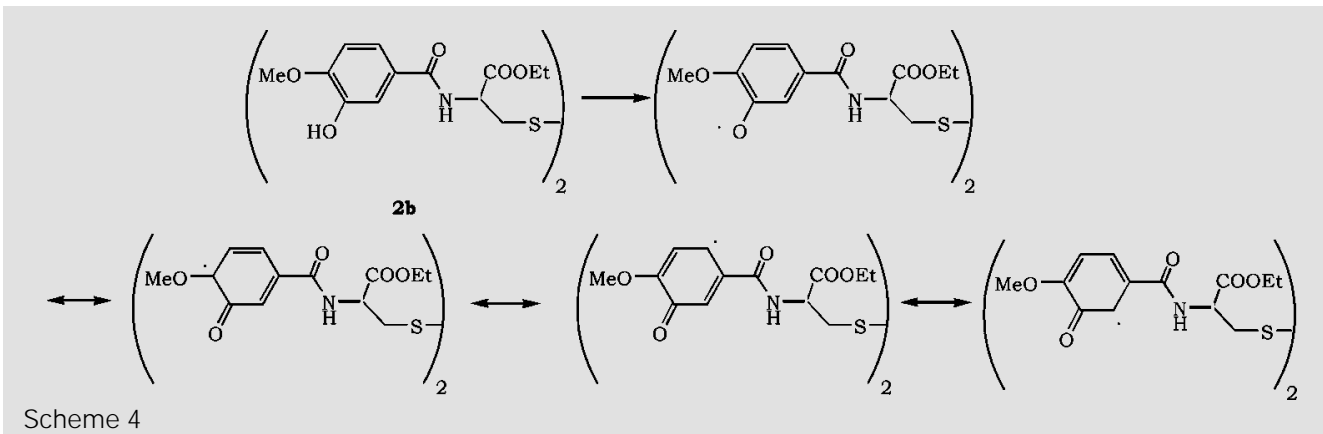


cal formed by $3 \mathrm{~b}$ is more stable than that formed by $1 \mathrm{~b}$, implying that this entity is generated more easily by the former than by the latter (Scheme 3).

In the same way, phenoxy radicals originating from compounds with a phenolic group meta to the amide and $\alpha-\beta$ ethylenic amide functions are less stable because of nonparticipation of carbonyl electrons. Such radicals are thus produced less easily than paraphenols (Scheme 4).

\section{Conclusion}

Novel donors of nitric oxide with anti- oxidant properties derived from $S$-nitrosocysteine were prepared.

Studies of NO release from $S$-nitrosothiols 1a-7a were carried out by ESR. The ability of disulfides $1 \mathrm{~b}-7 \mathrm{~b}$ to react with superoxide radicals was also investigated, showing that compounds with vanillic (1b) and ferulic ( $3 b)$ moieties are the most efficient antioxidants in this series towards $\mathrm{O}_{2}{ }_{2}^{-}$. For these two compounds, the respective IC 50 values are $92 \mu \mathrm{M}$ and $43 \mu \mathrm{M}$.

Both $S$-nitrosothiols 1 a and 3 a seem to be interesting novel NO donors for pharmacological, or indeed for clinical use.

\section{References}

1. Feelisch M \& Stamler J S (1996). Methods in Nitric Oxide Research. J Wiley \& Sons Ltd., New York.

2. Marletta MA (1993). Nitric oxide synthase structure and mechanism. J ournal of Biological Chemistry, 268: 12231-12234.

3. Culotta E \& Koshland J r DE (1992). NO news is good news. Science, 258: 1862 1865.

4. Stamler J S, Singel DJ \& LoscalzoJ (1992). Biochemistry of nitric oxide and its redoxactivated forms. Science, 258: 1898-1902.

5. Marletta MA, Yoon PS, lyengar R, Leaf CD \& Wishnok JS (1988). Macrophage oxidation of L-arginine to nitrite and nitrate: nitric oxide is an intermediate. Biochemistry, 27: 8706-8711.

6. Garthwaite J (1991). Glutamate, nitric oxide and cell-cell signalling in the nervous system. Trends in Neurosciences, 14: 6067.

7. McDonald B, Reep B, Lapetina EG \& Vedia LM (1993). Glyceraldehyde-3-phosphate dehydrogenase is required for the transport of nitric oxide in platelets. Proceedings of the National Academy of Sciences, USA, 90: 11122-11126.

8. Moncada S, Palmer RMJ \& Higgs EA (1991). Nitric oxide: physiology, pathophysiology, and pharmacology. Pharmacological Reviews, 43: 109-142.

9. Feelisch M \& Noack E (1987). Nitric oxide (NO) formation from nitrovasodilators occurs independently of hemoglobin or nonheme iron. European J ournal of Pharmacology, 142: 465-469.
10. Flitney FW, Megson IL, Flitney DE \& Butler AR (1992). Iron-sulphur cluster nitrosyls, a novel class of nitric oxide generator: mechanism of vasodilator action on rat isolated tail artery. British J ournal of Pharmacology, 107: 842-848.

11. Bourassa , DeGraff W, Kudo S, Wink DA, Mitchell J B \& Ford PC (1997). Photochemistry of Roussin's red salt, $\mathrm{Na}_{2}\left[\mathrm{Fe}_{2} \mathrm{~S}_{2}\right.$ $\left.(\mathrm{NO})_{4}\right]$, and of Roussin's black salt, $\mathrm{NH}_{4}\left[\mathrm{Fe}_{4} \mathrm{~S}_{3}(\mathrm{NO})_{7}\right]$. In situ nitric oxide generation to sensitive $\gamma$-radiation induced cell death. J ournal of the American Chemical Society, 119: 2853-2860.

12. Thatcher GRJ \& Weldon H (1998). NO problem for nitroglycerin: organic nitrate chemistry and therapy. Chemical Society Reviews, 27: 331-337.

13. Ji Y, Akerboom TPM \& Sies H (1996). Microsomal formation of S-nitrosoglutathione from organic nitrites: possible role of membrane-bound glutathione transferase. Biochemical J ournal, 313: 377380.

14. Feelisch $M$, Schönafinger $K \&$ Noack $E$ (1992). Thiol-mediated generation of nitric oxide accounts for the vasodilator action of furoxans. Biochemical Pharmacology, 44: 1149-1157.

15. Hwang KJ \& Kang H (1998). Design and synthesis of furoxan derivatives as probe for the nitric oxide generation. Bulletin of the Korean Chemical Society, 19: 506507.

16. Hrabie J A, Klose JR, Wink DA \& Keefer LK (1993). New nitric oxide-releasing zwit- terions derived from polyamines. J ournal of Organic Chemistry, 58: 1472-1476.

17. Southan GJ , Srinivasan A, George C, Fales HM \& Keefer LK (1998). N-nitrosated Nhydroxyguanidines are nitric oxide-releasing diazeniumdiolates. Chemical Communications, 1191-1192.

18. Décout J L, Roy $B$, Fontecave $M$, Muller J C, Williams PH \& Loyaux D (1995). Decomposition of FK 409, a new vasodilator: identification of nitric oxide as a metabolite. Bioorganic and Medicinal Chemistry Letters, 5: 973-978.

19. Oae S \& Shinhama K (1983). Organic thionitrites and related substances. A review. Organic Preparations and Procedures International, 15: 167-198.

20. Petit C, Hoffmann P, Souchard JP \& Labidalle S (1997). Synthesis and characterization of new aromatic thionitrites. Phosphorus, Sulfur and Silicon, and the Related Elements, 129: 59-67.

21. Stamler J S, Simon DI, Osborne JA, Mullins ME, J araki O, Michel T, Singel DJ \& LoscalzoJ (1992). S-nitrosylation of proteins with nitric oxide: synthesis and characterization of biologically active compounds. Proceedings of the National Academy of Sciences, USA, 89: 444-448.

22. Beckman J S, Beckman TW, Chen J, Marshall PA \& Freeman BA (1990). Apparent hydroxyl radical production by peroxynitrite: implications for endothelial injury from nitric oxide and superoxide. Proceedings of the National Academy of Sciences, USA, 7: 1620-1624. 
23. Castro L, Rodriguez M \& Radi R (1994). Aconitase is readily inactivated by peroxynitrite, but not by its precursor, nitric oxide. J oumal of Biological Chemistry, 269: 29409-29415.

24. Beckman J S \& Koppenol W (1996). Nitric oxide, superoxide, and peroxynitrite: the good, the bad, and the ugly. American J ournal of Physiology, 271: C1424-C1437.

25. J ovanovic SV, Steenken S, Tosic M,
Marjanovic B \& Simic MG (1994). Flavonoids as antioxidants. J ournal of the American Chemical Society, 116: 48464851.

26. Rice-Evans CA, Miller NJ \& Paganga G (1996). Structure-antioxidant activity relationships of flavonoids and phenolic acids. Free Radical Biology and Medicine, 20: 933-956

27. Komarov A, Mattson D, J ones M M, Singh
PK \& Lai CS (1993). In vivo spin trapping of nitric oxide in mice. Biochemical and Biophysical Research Communications, 195: 1191-1198.

28. McCord J \& Fridovich I (1969). Superoxide dismutase. An enzymic function for erythrocuprein (hemocuprein). J ournal of Biological Chemistry, 244: 6049-6055. 